\title{
A 48-month Clinical Evaluation of Fissure Sealants Placed With Different Adhesive Systems
}

\author{
E Karaman • AR Yazici $\bullet$ D Tuncer \\ E Firat $\bullet \mathrm{S}$ Unluer $\bullet \mathrm{M}$ Baseren
}

\section{Clinical Relevance}

Etch-and-rinse adhesive systems can be a better choice for ensuring the long-term success of fissure sealants.

*Emel Karaman, DDS, PhD, Faculty of Dentistry, Department of Restorative Dentistry, Ondokuz Mayıs University, Kurupelit, Samsun, Turkey

A. Rüya Yazici, DDS, PhD, Faculty of Dentistry, Department of Restorative Dentistry, Hacettepe University, Sihhiye, Ankara, Turkey

Duygu Tuncer, DDS, PhD, Faculty of Dentistry, Department of Restorative Dentistry, Başkent University, Bahçelievler, Ankara, Turkey

Esra Firat, DDS, PhD, Faculty of Dentistry, Department of Restorative Dentistry, Hacettepe University, Ankara, Turkey

Sengul Unluer, DDS, PhD, Oral and Tooth Health Center, Gaziantep, Turkey

Meserret Baseren, DDS, PhD,Hacettepe University, Faculty of Dentistry, Department of Restorative Dentistry, Sihhiye, Ankara, Turkey

*Corresponding author: Ondokuz Mayıs University, Faculty of Dentistry, Dept. of Restorative Dentistry, Kurupelit, Samsun, 55139, Turkey; e-mail: dtemelc@yahoo.com

DOI: $10.2341 / 12-181-\mathrm{C}$

\section{SUMMARY}

Aim: To compare the retention rates of a nanofilled occlusal fissure sealant placed with the use of an etch-and-rinse or a self-etch adhesive over 48 months.

Materials and Methods: The authors enrolled 244 teeth, each with no restoration or sealant and no detectable caries, from 16 patients. The sealants were placed with Solobond M twostep etch-and-rinse adhesive or Futurabond NR one-step self-etch adhesive by four previously calibrated dentists using a table of random numbers. After completion of the adhesive application, a nanofilled sealant, Grandio Seal, was applied and light-cured. Two other calibrated examiners, who were unaware of which adhesive had been used, independently evaluated the sealants at baseline and at 12-, 24-, 36-, and 48-month recalls. Each sealant was evaluated in terms of caries formation being present or absent and retention using the following criteria: $1=$ completely retained, $2=$ partial loss, and $3=$ total loss. The 
Pearson $\chi^{2}$ test was used to evaluate differences in retention rates among the sealants used with different adhesives for each evaluation period.

Results: The retention rates for sealants in the Solobond M group were significantly higher than those in the Futurabond NR group in all periods of evaluation $(p<0.05)$. No statistically significant difference between the retention rates for premolars and molars was found at each evaluation period $(p>0.05)$. There was no new caries formation throughout the 48-month recall period.

Conclusion: Fissure sealants placed with etchand-rinse adhesive showed better retention rates than those placed with self-etch adhesive.

\section{INTRODUCTION}

Dental caries is a global public health problem that can be effectively prevented and controlled through a combination of individual, community, and professional efforts. ${ }^{1}$ Although only 12.5 percent of all tooth surfaces are occlusal, most of the total caries experienced by children and adolescents proceeds from occlusal caries. ${ }^{2}$ As a result of the morphology of the pit and fissure surfaces there are stagnation areas, where the plaque formed is anatomically protected from even a single toothbrush filament by the dimensions of the fissure. ${ }^{3}$ Because preventive approaches, such as control of bacterial plaque and topical applications of fluoride, have little effect on pits and fissures, more effective treatments are necessary. ${ }^{4}$ Application of pit-and-fissure sealants are one of the treatment modalities that has been shown to be very effective in preventing occlusal caries by physical obstruction of the pits and fissures. ${ }^{5,6}$ Therefore, the clinical effectiveness and success of sealants have been equated with their retention. ${ }^{7}$ If the sealant is fully retained, then recurrent caries or progression of caries beneath the restoration is negligible. ${ }^{5}$ To enhance the longevity of pit-and-fissure sealants, several materials and techniques have been developed, including the use of adhesive systems under sealants. ${ }^{8,9}$

Bonding to enamel with the etch-and-rinse system is a reliable technique. Phosphoric acid etching removes contaminants and creates an irregular microporous enamel surface that is infiltrated by the resin-based sealant material. It has been reported that the highest bond strengths to human enamel were obtained using phosphoric acid etching and adhesives underneath the sealants. ${ }^{10,11}$ However, the taste, rinsing, and suction associated with the phosphoric acid etching stage may be unpleasant for patients. $^{12}$

Self-etch adhesive systems have been developed to simplify the bonding procedures, which significantly reduces the clinical application time and technique sensitivity because the enamel/dentin acid etching, rinsing, and drying steps are eliminated. ${ }^{13,14} \mathrm{Be}$ cause they have fewer operative steps and a shorter chairtime, self-etch adhesives may also be advantageous for treating pediatric patients. However, previous studies ${ }^{15,16}$ have reported that their adhesive performance with unground enamel is challenging. The literature includes limited documentation comparing the effects of etch-and-rinse and self-etch adhesive systems on clinical performance of pit-andfissure sealants, and the results are contradictory. Although some studies ${ }^{16-18}$ recommended the use of etch-and-rinse systems, one study reported that etch-and-rinse and self-etch systems cause similar results in terms of retention in vivo. ${ }^{12}$

In 2009, we reported detailed information about the clinical performance of fissure sealants placed with different adhesives for a 24-month period. ${ }^{18}$ As there is little information about the effectiveness of a self-etch adhesive application before fissure sealant placement, the aim of this clinical study was to compare the retention rates of a nanofilled occlusal fissure sealant placed with the use of an etch-andrinse adhesive or a self-etch adhesive after a longer follow-up period.

\section{MATERIALS AND METHODS}

The protocol and consent form for this study were reviewed and approved by the Hacettepe University Human Ethics Committee. Written informed consent for involvement in the study was obtained from all patients.

A total of 16 patients (15 women and 1 man) who were seeking routine dental care at the conservative dentistry clinics at the Hacettepe University, Faculty of Dentistry, were selected. Patients who participated in the current study had good general and oral health and hygiene. They also had no detecatable caries, bruxism, malocclusion, previously placed restorations or sealants on the fissures, or allergies to resins. The mean age of the patients was 20 years, and the patients ranged in age from 18 to 21 years.

Bitewing radiographs were taken. The fissures of teeth were then cleaned with a slurry of pumice applied with a bristle brush in a slow-speed 


\begin{tabular}{|c|c|c|c|c|c|c|c|c|}
\hline Evaluation $^{a}$ & \multicolumn{2}{|c|}{12 Months } & \multicolumn{2}{|c|}{24 Months } & \multicolumn{2}{|c|}{36 Months } & \multicolumn{2}{|c|}{48 Months } \\
\hline 2 (No. [\%]) & $8(6.6)$ & $16(13.1)$ & $12(10.5)$ & $12(10.5)$ & 19 (16.6) & $12(10.5)$ & $20(17.5)$ & $11(9.6)$ \\
\hline 3 (No. [\%]) & $5(4.1)$ & $81(66.4)$ & $9(7.9)$ & $84(73.7)$ & $9(7.8)$ & $89(78)$ & $12(10.5)$ & $93(81.5)$ \\
\hline Total No. & 122 & 122 & 114 & 114 & 114 & 114 & 114 & 114 \\
\hline
\end{tabular}

handpiece to remove salivary pellicle and any remaining plaque. By using a table of random numbers, four previously calibrated dentists placed a total of 244 sealants on the permanent premolars and molars with either Solobond M (Voco, Cuxhaven, Germany), a two-step etch-and-rinse adhesive, or Futurabond NR (Voco), a one-step self-etch adhesive. After completion of the adhesive application, a nanofilled sealant, Grandio Seal (Voco), was applied and gently teased through the fissure with the tip of a periodontal probe to prevent voids and air entrapment. Then, the applied fissure sealants were polymerized using a quartz-tungsten-halogen light (Hilux, Benlioglu, Ankara, Turkey). Light output of the curing unit was found to exceed $550 \mathrm{~mW} / \mathrm{cm}^{2}$ before and after the study, as verified with a radiometer. The occlusion was checked with articulation paper. Finishing and polishing were performed using fine-grit diamond burs (Diatech, Swiss Dental, Heerbrugg, Switzerland) and rubber cups (Edenta AG, AU SG, Switzerland). All of the materials were used according to the manufacturers' instructions, and moisture control was maintained by use of adapted cotton-roll isolation procedures and a chairside assistant.

Two other calibrated examiners (ARY, MB), who were unaware of which adhesive had been used, independently evaluated the sealants with the aid of a dental explorer and an introral mirror. At the beginning of the study, Kappa values were calculated to test the intra- and interexaminer reproducibility. The Kappa values were high (0.95) and showed powerful intra- and interexaminer agreement. Each sealant was evaluated in terms of caries formation as present or absent, and retention was evaluated using the following criteria:

1) Completely retained (CR)

2) Partial loss (PL)

3) Total loss (TL)

The Pearson $\chi^{2}$ test was used to evaluate differences in the retention rates of the sealants used with different adhesives for each evaluation period at a $5 \%$ level of significance.

\section{RESULTS}

Sixteen patients participated in this clinical study. The distrubution of sealant retention rates are displayed in Table 1. Differences between the retention rates of fissure sealants placed with Solobond $\mathrm{M}$ and Futurabond NR were statistically significant for all periods of evaluation $(p<0.05)$.

After 12 months, 134 fissure sealants of the 16 patients were completely retained. The retention rates of sealants placed with Solobond $\mathrm{M}$ and Futurabond NR were $89.3 \%$ and $20.5 \%$, respectively.

At the 24-month recall, one patient with 16 sealants could not be evaluated because of relocation to another city. Therefore, 228 sealants of 15 patients were available for evaluation. 111 teeth were fully sealed with the fissure sealant. The retention rate of the Solobond M group was found to be $81.6 \%$, whereas it was $15.8 \%$ for the Futurabond NR group, as previously reported. ${ }^{18}$

After 36 months, the retention rates of sealants placed with Solobond M and Futurabond NR were 


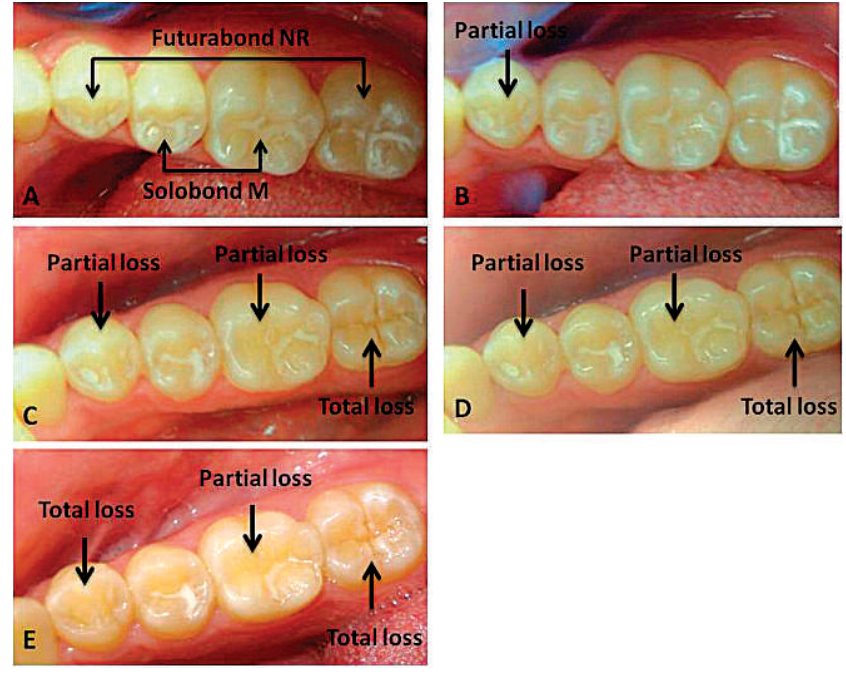

Figure 1. Fissure sealants at baseline (A), at 12 months (B), at 24 months (C), at 36 months (D), and at 48 months $(E)$.

$75.4 \%$ and $11.4 \%$, respectively. There were nine total losses with Solobond M and 89 total losses with Futurabond NR.

At the end of 48 months, 82 sealants from Solobond M group and 10 sealants from Futurabond NR group were evaluated as completely retained; the retention rates for the groups were $71.9 \%$ and $8.7 \%$, respectively. Twelve sealants from the Solobond M group were totally lost throughout the study; 93 were totally lost in the Futurabond NR group. Twenty sealants from the Solobond $\mathrm{M}$ group and 11 sealants from the Futurabond NR group were partially lost (Figure 1).
Distrubution of retention rates of premolars and molars are shown in Tables 2 and 3. No statistically significant differences were found between the retention rates of premolars and molars at each evaluation period. We did not observe caries development on any of the teeth during the 48 months.

\section{DISCUSSION}

Fissure sealants can be used for caries prevention in at-risk, caries-free teeth and as therapy for carious lesions limited to enamel (incipient caries). They are also appropriate as a conservative restoration in many situations in which caries extends into the dentin. This means that not only children, on which most sealant studies have focused, but also adults with appropriate indications can benefit from their use. ${ }^{19,20}$ Nevertheless, clinical trials involving children are hard to perform, as sealants are very technique sensitive. Success of the follow-up is also dependent on parent cooperation and motivation to bring the child for follow-up. Therefore, we evaluated sealant retention rates in adults.

The extent and depth of the etching pattern logically should influence the bonding performance of an adhesive, as enamel bonding is primarily based on micromechanical interlocking of a low-viscosity resin into microporosities. ${ }^{21}$ The depth of the enamel surface removed during the etching procedure can be affected by a number of factors, such as the type and concentration of acid, the duration of etching, and the chemical composition of the surface. ${ }^{22,23}$ It has been demonstrated that the application of a one-step self-etch adhesive did not create a deep enamel

Table 2: Distribution of Sealant Retention Rates of the Solobond M Group for Premolars and Molars

\begin{tabular}{|c|c|c|c|c|c|c|c|c|}
\hline \multirow{2}{*}{ Evaluation $^{a}$} & \multicolumn{2}{|c|}{12 Months } & \multicolumn{2}{|c|}{24 Months } & \multicolumn{2}{|c|}{36 Months } & \multicolumn{2}{|c|}{48 Months } \\
\hline & Premolar & Molar & Premolar & Molar & Premolar & Molar & Premolar & Molar \\
\hline 1 (No. [\%]) & $54(49)$ & $56(51)$ & 47 (50.3) & $46(49.7)$ & $40(46.5)$ & $46(53.4)$ & $37(45.1)$ & 45 (54.8) \\
\hline 2 (No. [\%]) & $1(12.5)$ & 7 (87.5) & $2(16.7)$ & 10 (83.3) & $8(42.1)$ & $11(57.8)$ & $8(4)$ & $12(6)$ \\
\hline 3 (No. [\%]) & $3(75)$ & $1(25)$ & $5(55.5)$ & $4(44.5)$ & $6(66.6)$ & $3(33.3)$ & $9(75)$ & $3(25)$ \\
\hline Total no. & 58 & 64 & 54 & 60 & 54 & 60 & 54 & 60 \\
\hline
\end{tabular}




\begin{tabular}{|c|c|c|c|c|c|c|c|c|}
\hline \multirow[t]{3}{*}{ Evaluation $^{a}$} & \multicolumn{8}{|c|}{ Futurabond NR } \\
\hline & \multicolumn{2}{|c|}{12 Months } & \multicolumn{2}{|c|}{24 Months } & \multicolumn{2}{|c|}{36 Months } & \multicolumn{2}{|c|}{48 Months } \\
\hline & Premolar & Molar & Premolar & Molar & Premolar & Molar & Premolar & Molar \\
\hline 2 (No. [\%]) & $5(31.2)$ & $11(68.7)$ & $4(33.3)$ & $8(66.7)$ & $5(41.7)$ & 7 (58.3) & $3(27.3)$ & $8(72.7)$ \\
\hline 3 (No. [\%]) & $39(48.1)$ & $42(51.9)$ & $40(47.7)$ & $44(52.3)$ & $44(49.4)$ & $45(50.6)$ & $47(50.5)$ & $46(49.5)$ \\
\hline
\end{tabular}

etching pattern compared to those of phosphoric acid. ${ }^{24,25}$ Dos Santos and others ${ }^{26}$ evaluated the penetration of adhesive materials into enamel before the application of a pit-and-fissure sealant and reported that etching with phosphoric acid exhibited significantly greater penetration than enamel treated with a self-etch adhesive. Beloica and others ${ }^{27}$ have reported that the microshear and microtensile bond strength to intact enamel of the recently introduced all-in-one adhesives was inferior to that of an etch-and-rinse system. Various studies have also indicated the potential benefit of additional phosphoric acid etching of enamel before application of a self-etch adhesive. ${ }^{28,29}$ Luhrs and others ${ }^{30}$ showed significantly increased shear bond strength values to enamel with the addition of phosphoric acid etching to self-etch adhesives. Another study also reported that pre-etching the intact enamel with $37 \%$ phosphoric acid resulted in the formation of longer resin tags and a higher depth of penetration of the resin tags of the self-etch adhesive (Clearfil SE bond); it also attained a higher bond strength to intact enamel. ${ }^{31}$

Consistent with our 24-month results, the sealant retention rates were higher for the Solobond $\mathrm{M}$ group at the 36- and 48-month recalls. In accordance with these findings, Venker and others ${ }^{32}$ reported that at the end of their 12-month clinical study, sealants placed with self-etch adhesives had lower retention rates compared with sealants placed with phosphoric acid etching. In another clinical study, the effects of a self-etch adhesive system and a conventional acid etching on retention of a fissure sealant were compared. ${ }^{17}$ It has been found that at the end of a 12-month period, the retention of the acid-etch group was significantly superior to that of the self-etch group. They concluded that the best practice for placement of sealants remains enamel preparation with acid etch and use of an intermediate bonding layer. ${ }^{17}$

Contrary to the findings of the current study, Feigal and Quelhas ${ }^{12}$ reported similar sealant retention rates using Prompt-L-Pop adhesive and conventional phosphoric acid etching without the use of any bonding agent in vivo. However, the results cannot be directly compared with our results, as no adhesive system was used in conjunction with the phosphoric acid. Moreover, it has been reported that the $\mathrm{pH}$ of Prompt-L-Pop was approximately one and was almost as aggressive as conventional phosphoric acid etching. ${ }^{24}$ Moura and others ${ }^{33}$ demonstrated a correlation between the $\mathrm{pH}$ of the adhesive systems and the level of morphological alterations of the enamel surface. Recently, it has been demonstrated that self-etch systems with higher $\mathrm{pH}$ values (AdheSE and Clearfil SE Bond) can have increased bond strength values when the application time is doubled. ${ }^{34}$ They found a significant correlation between $\mathrm{pH}$ and mean bond strengths. The low retention rates observed with Futurabond NR at each evaluation period of the current study may be related to the $\mathrm{pH}$ of the adhesive ( $\mathrm{pH}=1.4)$, which is considered to be a mild self-etch primer. This may have caused insufficient etching and deficient resin penetration of the selfetching priming agents into the fissure enamel. 
Nevertheless, achieving a sufficient etching pattern on unground enamel remains a problem for selfetching adhesives. ${ }^{15}$ The intact enamel surface is prismless, is hypermineralized, and contains more inorganic material than the inner enamel layer. ${ }^{35} \mathrm{By}$ using etch-and-rinse adhesive systems, the prismless enamel surface layer is removed because of the phosphoric acid etching and subsequent water rinsing of the etched enamel. Therefore, sufficient microretentive bonding of the fissure sealant can be provided by the exposure of the prismatic structured enamel. In contrast, treatment with self-etching priming agents does not remove a significant amount of the prismless enamel surface layer, as no rinsing takes place after application of the primer. ${ }^{15,21} \mathrm{It}$ is possible that the prismless enamel surface layer prevents the permeation of self-etching primers, thus leaving some areas partially unetched. ${ }^{15}$ It has recently been shown that self-etching primers produce high-tensile bond strengths when enamel is roughened but lower tensile bond strengths when enamel is left unprepared. ${ }^{15,16}$

Before acid etching and sealant application, it is important to make sure that the fissures are free from plaque and debris, which may influence the etching and sealing pattern. ${ }^{36}$ In the current study, prophylaxis was performed with pumice before the sealant placement. The remaining pumice and debris in the fissures could be another reason for the lower retantion rates of the Futurabond NR group, as its etching capacity is not high enough to remove remnants from the fissures. However, the etching capacity of phosphoric acid has been reported to be high enough to remove those remnants. ${ }^{36}$

Studies on sealant retention by tooth type report that premolars have the highest sealant retention rates and second molars have the lowest. ${ }^{37-39}$ However, no statistically significant difference was found between the retention rates for premolars and molars in the current study.

\section{CONCLUSION}

This clinical study has demonstrated that, over a 48month period, fissure sealants placed with an etchand-rinse adhesive showed significantly higher retention rates than those placed with a self-etch adhesive. Further clinical studies are needed to confirm the reproducibility of these findings.

\section{Acknowledgement}

We would like to thank Voco for supplying the materials used in our study.

\section{Conflict of Interest}

The authors of this manuscript certify that they have no proprietary, financial, or other personal interest of any nature or kind in any product, service, and/or company that is presented in this article.

(Accepted 5 September 2012)

\section{REFERENCES}

1. Filstrup SL, Briskie D, da Fonseca M, Lawrence L, Wandera A, \& Inglehart MR (2003) Early childhood caries and quality of life: child and parent perspectives Pediatric Dentistry 25(5) 431-440.

2. Batchelor PA, \& Sheiham A (2004) Grouping of tooth surfaces by susceptibility to caries: a study in 5-16 yearold children BMC Oral Health 4(1) 2.

3. Subramaniam P, Konde S, \& Mandanna DK (2008) Retention of a resin-based sealant and a glass ionomer used as a fissure sealant: a comparative clinical study Journal of the Indian Society of Pedodontics and Preventive Dentistry 26(3) 114-120.

4. Ripa LW (1980) Occlusal sealants: rationale and review of clinical trials International Dental Journal 30(2) 127-139.

5. Ahovuo-Saloranta A, Hiiri A, Nordblad A, Makela M, \& Worthington HV (2008) Pit and fissure sealants for preventing dental decay in the permanent teeth of children and adolescents Cochrane Database Systematic Review 8(4) CDOO1830.

6. Mejare I, Lingstrom P, Petersson LG, Holm AK, Twetman S, Kallestal C, Nordenram G, Lagerlöf F, Söder B, Norlund A, Axelsson S, \& Dahlgren H (2003) Cariespreventive effect of fissure sealants: a systematic review Acta Odontologica Scandinavica 61(6) 321-330.

7. Weintraub JA (2001) Pit and fissure sealants in highcaries-risk individuals Journal of Dental Education 65(10) 1084-1090.

8. Choi JW, Drummond JL, Dooley R, Punwani I, \& Soh JM (1997) The efficacy of primer on sealant shear bond strength Pediatric Dentistry 19(4) 286-288.

9. Hitt JC, \& Feigal RJ (1992) Use of a bonding agent to reduce sealant sensitivity to moisture contamination: an in vitro study Pediatric Dentistry 14(1) 41-46.

10. Feigal RJ, Musherure P, Gillespie B, Levy-Polack M, Quelhas I, \& Hebling J (2000) Improved sealant retention with bonding agents: a clinical study of two-bottle and single-bottle systems Journal of Dental Research 79(11) 1850-1856.

11. Perez-Lajarin L, Cortes-Lillo O, Garcia-Ballesta C, \& Cozar-Hidalgo A (2003) Marginal microleakage of two fissure sealants: a comparative study Journal of Dentistry for Children (Chicago, Ill) 70(1) 24-28.

12. Feigal RJ, \& Quelhas I (2003) Clinical trial of a selfetching adhesive for sealant application: success at 24 months with Prompt L-Pop American Journal of Dentistry 16(4) 249-251.

13. Perdigao J, Geraldeli S, Heymann HO, \& Rosa BT (2000) Effect of conditioner and restorative resin on enamel bond strengths American Journal of Dentistry 13(2) 88-92. 
14. Van Meerbeek B, De Munck J, Yoshida Y, Inoue S, Vargas M, Vijay P, Van Landuyt K, Lambrechts P, \& Vanherle G (2003) Buonocore memorial lecture. Adhesion to enamel and dentin: current status and future challenges Operative Dentistry 28(3) 215-235.

15. Kanemura N, Sano H, \& Tagami J (1999) Tensile bond strength to and SEM evaluation of ground and intact enamel surfaces Journal of Dentistry 27(7) 523-530.

16. Perdigao J, \& Geraldeli S (2003) Bonding characteristics of self-etching adhesives to intact versus prepared enamel Journal of Esthethic and Restorative Dentistry 15(1) 32-41 discussion 42.

17. Burbridge L, Nugent Z, \& Deery C (2007) A randomized controlled trial of the effectiveness of a one-step conditioning agent in sealant placement: 12-month results European Archives of Paediatric Dentistry 8(1) 49-54

18. Yazici AR, Karaman E, Baseren M, Tuncer D, Yazici E, \& Unluer S (2009) Clinical evaluation of a nanofilled fissure sealant placed with different adhesive systems: 24-month results Operative Dentistry 34(6) 642-647.

19. Beauchamp J, Caufield PW, Crall JJ, Donly K, Feigal R, Gooch B, Ismail A, Kohn W, Siegal M, \& Simonsen RJ (2008) Evidence-based clinical recommendations for the use of pit-and-fissure sealants: a report of the American Dental Association Council on Scientific Affairs Journal of the American Dental Association 139(3) 257-268.

20. Swift EJ Jr (1987) Preventive resin restorations Journal of the American Dental Association 114(6) 819-821.

21. Hannig M, Bock H, Bott B, \& Hoth-Hannig W (2002) Inter-crystallite nanoretention of self-etching adhesives at enamel imaged by transmission electron microscopy European Journal of Oral Sciences 110(6) 464-470.

22. Bates D, Retief DH, Jamison HC, \& Denys FR (1982) Effects of acid etch parameters on enamel topography and composite resin-enamel bond strength Pediatric Dentistry 4(2) 106-110.

23. Blosser RL (1990) Time dependence of $2.5 \%$ nitric acid solution as an etchant on human dentin and enamel Dental Materials 6(2) 83-87.

24. Pashley DH, \& Tay FR (2001) Aggressiveness of contemporary self-etching adhesives. Part II: etching effects on unground enamel Dental Materials 17(5) 430-444.

25. Shinohara MS, de Oliveira MT, Di Hipolito V, Giannini M, \& de Goes MF (2006) SEM analysis of the acid-etched enamel patterns promoted by acidic monomers and phosphoric acids Journal of Applied Oral Science 14(6) 427-435.

26. dos Santos KT, Sundfeld RH, Garbin CA, de Alexandre RS, Sundefeld ML, \& Ceolim BN (2008) Lenght of resin tags in pit-and-fissure sealants: all-in-one self-etch adhesive vs phosphoric acid etching Compendium of Continuing Education in Dentistry 29(3) 186-192.
27. Beloica M, Goracci C, Carvalho CA, Radovic I, Margvelashvili M, Vulicevic ZR, \& Ferrari M (2010) Microtensile vs microshear bond strength of all-in-one adhesives to unground enamel Journal of Adhesive Dentistry 12(6) 427-433.

28. Van Landuyt KL, Kanumilli P, De Munck J, Peumans M, Lambrechts P, \& Van Meerbeek B (2006) Bond strength of a mild self-etch adhesive with and without prior acidetching Journal of Dentistry 34(1) 77-85.

29. Van Meerbeek B, Kanumilli P, De Munck J, Van Landuyt K, Lambrechts P, \& Peumans M (2005) A randomized controlled study evaluating the effectiveness of a two-step self-etch adhesive with and without selective phosphoricacid etching of enamel Dental Materials 21(4) 375-383.

30. Luhrs AK, Guhr S, Schilke R, Borchers L, Geurtsen W, \& Gunay H (2008) Shear bond strength of self-etch adhesives to enamel with additional phosphoric acid etching Operative Dentistry 33(2) 155-162.

31. Devarasa GM, Subba Reddy VV, Chaitra NL, \& Swarna YM (2012) Self-etching adhesive on intact enamel, with and without pre-etching Microscopy Research and Technique 75 (5) 650-654.

32. Venker DJ, Kuthy RA, Qian F, \& Kanellis MJ (2004) Twelve-month sealant retention in a school-based program using a self-etching primer/adhesive Journal of Public Health Dentistry 64(4) 191-197.

33. Moura SK, Pelizzaro A, Dal Bianco K, de Goes MF, Loguercio AD, Reis A, \& Grande RH (2006) Does the acidity of self-etching primers affect bond strength and surface morphology of enamel? Journal of Adhesive Dentistry 8(2) 75-83.

34. Perdigao J, Gomes G, \& Lopes MM (2006) Influence of conditioning time on enamel adhesion Quintessence International 37(1) 35-41.

35. Gwinnett AJ (1973) Human prismless enamel and its influence on sealant penetration Archives of Oral Biology 18(3) 441-444.

36. Garcia-Godoy F, \& Medlock JW (1988) An SEM study of the effects of air-polishing on fissure surfaces Quintessence International 19(7) 465-467.

37. Chan DC, Summitt JB, Garcia-Godoy F, Hilton TJ, \& Chung KH (1999) Evaluation of different methods for cleaning and preparing occlusal fissures Operative Dentistry 24(6) 331-336.

38. Messer LB, Calache H, \& Morgan MV (1997) The retention of pit and fissure sealants placed in primary school children by Dental Health Services Victoria Australian Dental Journal 42(4) 233-239.

39. Yazici AR, Kiremitci A, Celik C, Ozgunaltay G, \& Dayangac B (2006) A two-year clinical evaluation of pit and fissure sealants placed with and without air abrasion pretreatment in teenagers Journal of the American Dental Association 137(10) 1401-1405. 